\title{
THE EXPANSION VIEW OF THICK CONCEPTS
}

\author{
Brent G. Kyle \\ U.S. Air Force Academy
}

This paper proposes a new Separabilist account of thick concepts, called the Expansion View (or EV). According to EV, thick concepts are expanded contents of thin terms. An expanded content is, roughly, the semantic content of a predicate along with modifiers. Although EV is a form of Separabilism, it is distinct from the only kind of Separabilism discussed in the literature, and it has many features that Inseparabilists want from an account of thick concepts. EV can also give non-cognitivists a novel escape from the AntiDisentangling Argument. §I explains the approach of all previous Separabilists, and argues that there's no reason for Separabilists to take this approach. §II explains EV. §III fends off objections. And §IV explains how non-cognitivist proponents of EV can escape the AntiDisentangling Argument.

Ethicists often debate whether thick evaluative concepts, like kind, are composed of more fundamental concepts, like good. ${ }^{1}$ Separabilists hold that thick concepts are combinations of more fundamental elements, such as thin concepts and non-evaluative concepts. Inseparabilists, by contrast, claim that thick concepts cannot be divided into evaluative and non-evaluative components.

Separabilists must face an objection. If thin concepts are incapable of representing properties, as many non-cognitivists believe, it appears the thick concept's non-evaluative content must fully determine what property the thick concept represents. And this implies something problematic - that an outsider could know what the thick concept applies to without grasping its evaluative perspective. This is the AntiDisentangling Argument, originating with John McDowell (1981) and advocated by many Inseparabilists.

This paper proposes a new Separabilist model that's neutral between cognitivism and noncognitivism but can give non-cognitivists a novel escape from the Anti-Disentangling Argument. §I explains the basic approach of all previous Separabilists, and argues that there's no reason for Separabilists to take this approach. §II explains a different kind of Separabilist model, called the Expansion View (henceforth

${ }^{1}$ Italicized expressions refer to concepts; expressions with single-quotes refer to terms. I assume concepts are the semantic contents of terms that express them, and that concepts and semantic contents are on the level of sense rather than reference. 
EV). EV holds that thick concepts (e.g. kind) are expanded contents of thin terms (e.g. 'good'). An expanded content is, roughly, the semantic content of a predicate along with modifiers (e.g. 'good to others'). After objections are addressed, §IV shows that EV gives non-cognitivists a new escape from the Anti-Disentangling Argument. There, it's proposed that a thin concept can play a role in determining what property is represented by its associated thick concept, even if that thin concept doesn't represent a property by itself. The precedent for this idea comes from semantically incomplete expressions, such as 'ready'. These expressions arguably fail to represent properties, although their contents can play a role in determining what properties are represented by expanded contents, such as ready-to-dance.

$\mathrm{EV}$ assumes that at least some thick terms are evaluative as a matter of semantic content. ${ }^{2} \mathrm{EV}$ is only meant to hold for these semantically evaluative thick terms. Henceforth, the labels 'thick' and 'thin' will be reserved for terms and concepts that are semantically evaluative, unless otherwise noted.

This paper, however, does not argue that EV is true, or more plausible than rival accounts. It only argues that there's no reason to think EV is false. This modest claim is nevertheless important. It reveals that there are more ways of understanding thick concepts than both Separabilists and Inseparabilists have acknowledged. As explained in §I, all previous Separabilist models fall under a certain type, called a dependence view. And their Inseparabilist opponents often assume Separabilists should accept a dependence view. But EV is not a dependence view; and the debate between Separabilism and Inseparabilism has yet to countenance a model like EV. So, the modest claim of this paper makes room for a different kind of view within a broader debate. Positive arguments for EV must be discussed elsewhere.

Although EV is a form of Separabilism, it possesses many features that Inseparabilists want from an account of thick concepts. As we'll see, EV is consistent with anti-disentangling (§IV), shapelessness

\footnotetext{
${ }^{2}$ Space prohibits discussing this assumption. Opponents include Väyrynen (2013) and Blackburn (1992). See Kyle
} (2013a; 2015) for defenses. 
(§IV.5), the denial of thin centralism (§II.4), the variability of thick terms (§III.2), and the ambivalence of thick terms and concepts (§III.2).

\section{Dependence Views}

Separabilists hold that thick concepts combine an evaluative content E with a non-evaluative content N. ${ }^{3}$

But how exactly are E and $\mathrm{N}$ combined? So far, all Separabilist models have held that $\mathrm{E}$ and $\mathrm{N}$ are combined by a dependence relation. On Allan Gibbard's view, E obtains "for" or because of N $(1992,280) .{ }^{4}$ Stephan Burton and Christine Tappolet hold that E obtains "in virtue of some particular instance" of N (Burton 1992, 31; Tappolet 2004, 216). Daniel Elstein and Thomas Hurka propose that N "makes anything" that has it E $(2009,521)$. And Andrew Payne allows that E and N may be interdependent - E obtains "in virtue of" N's obtaining, while E's obtaining can also be a “reason for” N (2005, 93). Let's call these dependence views. The defining feature of dependence views is that they require each thick concept to contain some conceptual component that represents a dependence relation (e.g. the concept in-virtue-of). ${ }^{5}$

All previous Separabilist models classify as dependence views. Indeed, their Inseparabilist opponents often assume Separabilists should accept a dependence view. Jonathan Dancy writes

A regrettably lewd action is not of such and such a sort, and bad; it is bad for being of that sort. All should accept that the evaluation is linked to the description in this way; we are not dealing here with a mere conjunction $(2013,45)$.

Another Inseparabilist, Debbie Roberts, lays out the groundwork for Separabilism as follows:

[A]n analysis that was merely conjunctive would not capture an aspect of what is conveyed by 'tactful': that it is due to its being $T$ that the action is good. Thus, a two-component analysis of 'tactful' would have to say something like: " $\mathrm{x}$ is tactful if and only if $\mathrm{x}$ is $\mathrm{T}$ and is good in virtue of being T.” (2011, 496).

\footnotetext{
${ }^{3}$ Some views allow $\mathrm{N}$ to embed thin concepts (e.g. Elstein and Hurka 2009). EV does as well.

${ }^{4}$ On his view, the evaluative content is the warranting of a certain feeling (e.g. shame) which is warranted "for" the fact that certain non-evaluative contents obtain.

${ }^{5}$ Dependence views are not explicit about whether the dependence relation between $\mathrm{E}$ and $\mathrm{N}$ is necessary or contingent, conceptual or metaphysical, etc.
} 
Both Dancy and Roberts assume Separabilists should accept a dependence view. And their assumption is not idle. As I note in §IV.2, Roberts relies on this assumption to show that some Separabilist views are vulnerable to the Anti-Disentangling Argument.

In this section, I argue against the prevailing assumption that Separabilists should accept a dependence view. I do not argue that dependence views are false; I only argue that Separabilists have no reason to accept a dependence view. In particular, I argue that Separabilists have no reason to think every thick concept contains a conceptual component that represents a dependence relation. Let's consider four potential reasons, which all fail.

A first reason may stem from Roberts' suggestion that a dependence relation is an "aspect of what is conveyed" by the term; the thick term conveys "that it is due to its being $T$ that the action is good" (2011, 496). This claim is not obviously so. Even if it's true, one must establish that the conveyed dependence relation is represented by some component of the thick concept. But there are many other ways for this information to be conveyed. For example, it might be conveyed pragmatically, or it might be entailed by the thick concept without being a component of that concept (just as colored is entailed by red without being a component of red). Roberts' suggestion doesn't rule out these possibilities, and so doesn't establish that each thick concept contains a component that represents a dependence relation.

A second argument might assume a dependence constraint such as (DC): it is conceptually true that $\mathrm{x}$ is good only if $\mathrm{x}$ is good in virtue of some property N (Zangwill 2006, 270; Roberts 2017, 216). (DC) forges a conceptual connection between the concept in-virtue-of and the concept good. Now suppose that good is a component of kind, as Separabilists may hold. From these assumptions, it may appear to follow (by transitivity) that in-virtue-of is also a component of kind. This conclusion, however, does not follow. To appeal to transitivity, the argument needs another premise - that in-virtue-of is a component of good. But it's controversial that good has any components. And more importantly, this extra premise is not supported by (DC). There are conceptual truths involving goodness that don't specify components of good, just as 
there are conceptual truths involving redness that don't specify components of red (e.g. redness is a color). And (DC) is appears to be the sort of conceptual truth that doesn't specify a component of good. After all, if good contained good-in-virtue-of- $N$ as a component, then good would be a component of itself, which is arguably impossible.

To be sure, we could state the dependence constraint in terms of kindness, rather than goodness. Consider (DC*): it is conceptually true that $\mathrm{x}$ is kind only if $\mathrm{x}$ is kind in virtue of some property $\mathrm{N}$. This constraint also doesn't entail that in-virtue-of is a component of kind. Again, there are conceptual truths involving kindness that don't specify components of kind. And (DC*) is surely among them, because kindin-virtue-of- $N$ cannot be a component of kind. Thus, dependence constraints like (DC) and (DC*) do not entail a dependence view of thick concepts, even if we assume Separabilism. ${ }^{6}$

A third argument for dependence views might stem from the reductive nature of Separabilism. (1) An account of thick concepts is not Separabilist unless it's reductive. But (2) such an account is not reductive unless it reduces a thick concept's evaluative element to something non-evaluative. And (3) the reduction of this evaluative element requires the specification of a dependence relation. So, Separabilism requires the specification of a dependence relation. However, (2) is false. Separabilism need only be reductive in the sense that it reduces a thick concept to evaluative and non-evaluative contents that are more fundamental than the thick concept itself_ — call this Weak Separabilism. A stronger form of Separabilism would also require that these constituent contents be expressible without thick terms — call this Strong Separabilism. ${ }^{7}$ Either way, Separabilism need not reduce a thick concept's evaluative element to something non-evaluative (Väyrynen 2016, sec. 3). This is the aim of many cognitivist and non-cognitivist theories, but not Separabilism per se.

\footnotetext{
${ }^{6}$ The same basic problems would arise if these constraints were framed in terms of supervenience, rather than dependence (although supervenience is not technically a dependence relation).

${ }^{7}$ Most Separabilists are Strong Separabilists. Tappolet is a Weak Separabilist — she reduces concepts like courage to affective concept like admirable $(2004,216)$, and assumes that affective concepts are thick (211).
} 
A fourth argument may stem from the failure of a simpler model, where $\mathrm{E}$ and $\mathrm{N}$ are combined by mere conjunction. Suppose we hold that brutal is the mere conjunction of bad and causing-pain-aggressively. These evaluative and non-evaluative contents can obtain coincidentally, without the act being brutal. Imagine that a physician aggressively causes pain by resetting a broken leg. Such an act would not ordinarily count as bad or brutal. But suppose the physician is breaking a promise to an irrelevant third party in resetting the patient's leg. Here the act of aggressively causing pain could be bad without being brutal. The conjunctive model has trouble excluding such coincidences. But dependence views can exclude them — the badness of a brutal act must somehow depend on the aggressive causing of pain, but the badness of the physician's act depends on the breaking of a promise. ${ }^{8}$

However, the ability to solve this problem supports dependence views only if no other model can solve it as effectively. And notice that we can explain why the promise-breaking physician's act isn't brutal without even referencing a dependence relation — roughly, brutality requires being bad to someone, but the promise-breaking physician isn't being bad to the patient or anyone else. ${ }^{9}$ As we'll see in $§ I I .3$, EV can provide this sort of explanation. We will also see that there's no general reason to think coincidences can present problems for EV.

A final reason for dependence views may stem from their putative ability to escape the AntiDisentangling Argument (e.g. Elstein and Hurka 2009; Burton 1992). But §IV shows that EV can also escape this argument. So, we're left to wonder why Separabilists should accept a dependence view rather than some alternative model.

\footnotetext{
${ }^{8}$ For additional discussion on such coincidences, see Kyle (2013b).

${ }^{9}$ More precisely, she's not being bad to anyone aggressively — see §II.3.
} 


\section{Expansion View}

EV holds that thick concepts are expanded contents of thin terms. This section first distinguishes thin from thick, highlights some key thin terms that are useful for EV, and then explains expanded contents. Finally, instances of EV are sketched and discussed.

II.1. Thin Terms. Thick and thin are technical notions that rarely get distinguished in theoretically neutral ways (Eklund 2011, 26-8; Väyrynen 2016, §5; Kyle 2016, §4). It’s beyond the scope of this paper to reject rival ways of drawing the distinction. The following is merely an explanation of how it should be understood for the purposes of EV.

The basic idea is that thick concepts require competent users to recognize an entailment to a logically weaker evaluative concept, whereas thin concepts do not require this. We can define logical weakness for concepts just as logicians define logical weakness for formulas (e.g. Tomassi 1999, 83). Accordingly, a concept C1 is logically weaker than C2 if and only if C2 entails C1 but not vice-versa. ${ }^{10}$ This definition is assumed in the following necessary condition for thickness. For any semantically evaluative concept $T$,

$T$ is a thick concept only if there is a logically weaker evaluative concept $E$ such that, necessarily, whoever fully grasps $T$ believes that $x$ is $T$ only if $x$ is $E .^{11}$

We can see that paradigmatic thick concepts satisfy this condition by considering conceptual-defectiveness judgments. If Sue believes that $\mathrm{x}$ is kind and that $\mathrm{x}$ is not good to anyone, then Sue must have a deficient grasp of kind - in this case, the relevant $\mathrm{E}$ is good-to-someone. If Jane believes that $\mathrm{x}$ is admirable and that $\mathrm{x}$ is not worthy of anything, then Jane must have a defective grasp of admirable - here, the relevant E is worthy-

${ }^{10}$ Logical weakness helps to capture one sense in which a particular thin concept like good is more general than certain thick concepts like kind - the former is logically weaker, and so has a wider extension, than the latter. However, ethicists likely mean something else when they construe thin versus thick in terms of general versus specific. Thanks to an anonymous reviewer for pointing this out.

${ }^{11}$ This condition can be weakened by replacing 'believes' with 'is disposed to believe'. 
of-something. And if Max believes that $\mathrm{x}$ is loyal and that $\mathrm{x}$ is not true to anything, then Max has a deficient grasp of loyal - here, true-to-something is the relevant E. ${ }^{12}$

What then are thin terms and concepts? For our purposes, a thin concept is any semantically evaluative concept that fails the above necessary condition for thickness. A thin term is a single word whose semantic content is a thin concept. And a thick term is a single word whose semantic content is a thick concept.

In principle, EV could appeal to many different thin terms (e.g. 'obligated', 'permitted', etc.). But this paper focuses on a small sample of thin terms that are particularly useful for EV. These are featured as predicates in the following sentences:

(1) Jane is good.

(2) Sue is worthy.

(3) Max has been true. ${ }^{13}$

These predicates also have antonyms - 'bad', 'unworthy', and 'untrue'. All claims about 'good', 'worthy', and 'true' apply similarly to their antonyms.

It's clear that 'good' and 'worthy' are thin terms, by our definition. Focus on worthy: the evaluative concept good-in-a-way might be logically weaker than worthy, assuming Judith Thomson is right that everything is good in some way or other $(2008,10)$. But one need not evince a deficient grasp of worthy by thinking that Sue is worthy and is not good in any way. One could easily think this if one believes that Sue is worthy of blame. The same strategy can be employed for any evaluative concept that's logically weaker than worthy.

It's worth pausing on (3). 'True' is plausibly an evaluative term, at least given its meaning in (3). It's normally positive to say that Max has been true and negative to say that he's been untrue. It's also

\footnotetext{
${ }^{12}$ I argue that 'true' is evaluative below. It's worth noting that 'true' is not coextensive with 'loyal'. One can be true to almost anything, but there are substantive restrictions on what one can be loyal to- e.g. one could be true to one's emotions, but not loyal to one's emotions.

${ }^{13}$ (3) is stated in the perfect tense (i.e. 'has been true'), because this is more natural when 'true' is applied to a person.
} 
useful to contrast (3) with 'Max has been firm'. Although similar in meaning, the latter is neutral whereas (3) typically expresses something positive. ${ }^{14}$ One might object that even non-evaluative sentences can express something positive - for example, 'Max is happy' expresses a positive state of affairs. However, 'Max is happy' doesn't express approval of Max. Neither does 'Max has been firm'. (3), by contrast, expresses approval of Max, much like how (1) expresses approval of Jane. And this is a crucial mark of an evaluative term.

Of course, it seems possible for speakers to use 'true' to express a negative evaluation. Seeing that Max didn't turn against his crime boss, the police might express their frustration as follows_- "Dammit! Max has been true." ${ }^{15}$ But the same goes for paradigmatic evaluative terms, like 'excellent' . Knowing that we cannot defeat the Lakers when Lebron is playing well, we might say_ “Dammit! Lebron has been excellent this game." This suggests that uses of both 'true' and 'excellent' can be variable in evaluative valence. But this is compatible with them being evaluative terms. Pekka Väyrynen has successfully argued that the variability of an expression doesn't preclude it from being semantically evaluative (2011). ${ }^{16}$

Furthermore, it's plausible that 'true' is a thin term by our definition, because true fails the necessary condition on thickness. Most likely, good-in-a-way is logically weaker than true. But one need not evince a deficient grasp of true by thinking that Max has been true and is not good in any way. One could think this if one believes that Max has been true to an evil cause. Moreover, the fact that one can be true to an evil cause is compatible with the claim that true is a thin concept. The concept true operates similar to

\footnotetext{
${ }^{14}$ In addition to evaluative differences, 'true' and 'firm' also differ in extension. It's possible to be firm in something without being true to that thing. A dishonest car salesman might be firm in a particular deal, without being true to that deal, because he fails to uphold his end of the bargain. One can also be true to something without being firm (or unwavering). Suppose Max is only true to his emotions. If his emotions fluctuate constantly, he might be quite erratic, and thus hard to classify as firm or unwavering.

15 Thanks to an anonymous reviewer for the example, and for pressing this objection.

${ }^{16}$ I cannot here provide a complete argument for the claim that 'true' is semantically evaluative. Suffice it to say that 'true' is just as likely to be semantically evaluative as any paradigmatic thick or thin term. Any argument against the claim that 'true' is semantically evaluative would be an equally plausible argument against taking 'courageous' or 'good' to be semantically evaluative. Roberts (2015, 912-3) points out that Väyrynen's arguments for the pragmatic view over-generate by showing that even 'good' isn't semantically evaluative.
} 
good in this regard. Clearly one can be good to an evil person, and good is the paradigm of thin concepts. A similar point applies to the word 'true': the fact that 'true' has variable uses doesn't preclude it from being a thin term. Expressions like 'good liar' suggest that thin terms like 'good' can also have variable uses. And Simon Kirchin has recently argued that various other thin terms are variable $(2017,133)$. I return to variability in §III.2.

One might object that 'true' is not thin, because it's not wholly evaluative. But the present distinction between thick and thin doesn't require the thin to be wholly evaluative. And there's no reason to require this. It's often asserted that thin terms are wholly evaluative, but the assertion is never supported by argument, and has been challenged on independent grounds (e.g. Väyrynen 2013, 7). Even noncognitivists can deny that thin terms are wholly evaluative. A thin term can be incapable of representing a property, in accord with traditional non-cognitivism, even if it has non-evaluative content. ${ }^{17}$ Indeed, the earliest known distinction between thick and thin comes from a non-cognitivist - R.M. Hare — who plainly assumes that all thin terms have non-evaluative content $(1952,121 ; 1963,25)$. And Hare is a main target of the Anti-Disentangling Argument. We will therefore not assume that thin terms are wholly evaluative.

The above distinction between thick and thin cannot be given a complete defense here. The important point is that it at least provides a principled distinction between 'good', 'worthy', and 'true', on the one hand, and paradigmatic thick terms, on the other. Without a complete defense, we can simply take the definition of a thin term as a stipulation that plays a key role in EV. Those who object to this use of 'thin' can simply replace 'thin' with another technical term, defined in the same way. This would make no difference for EV.

\footnotetext{
${ }^{17}$ The label 'descriptive' requires an aptness for representing properties, but 'non-evaluative' does not. Partly nonevaluative concepts can fail to represent properties.
} 
II.2. Expanded Contents. Corresponding to any predicate P, there are innumerable complex expressions that result merely from adding modifiers to P. Regarding 'good', there are expressions like 'good at dancing', 'good with children', 'good to others', etc. The same goes for non-evaluative predicates. Corresponding to 'ready', there are expressions like 'ready to dance', 'ready for work', etc. The semantic contents of these complex expressions are expanded contents of 'good' and 'ready' respectively. Expanded contents are defined as follows: For any predicate $\mathrm{P}$ and any concept $C$,

$C$ is an expanded content of $\mathrm{P}$ if and only if there is a possible expression $\mathrm{P} *$ such that $\mathrm{P} *$ results merely from adding modifiers to $\mathrm{P}$ and $C$ would be the semantic content of $\mathrm{P} *$.

Expanded contents always contain extra contents that are not determined solely by the associated predicate. These extra contents will be displayed in brackets - e.g. good-[at-dancing]. ${ }^{18}$

There are indefinitely many expanded contents for a given predicate, one for each possible combination of possible modifiers. An expanded content of, say, 'good' need not be expressible within any actual language. It only needs to be expressible in some possible language that contains 'good' with its actual meaning.

Among others, EV focuses on good+modifier phrases — complex phrases where 'good' is modified by other expressions (e.g. 'good to others'). It is uncontroversial that some such phrases contain occurrences of 'good' that are logically attributive (Almotahari and Hosein 2015, 1488; Peace 2017, 2992 3). That is, some sentences of the form 'A is good+modifier' are not equivalent to the conjunction of 'A is good' with a sentence that captures the modifier. For instance, 'A is good at dancing' is not equivalent to 'A is good' and 'A can dance'—otherwise absurdities would result (Szabó 2001, sec. 3). EV fully accords with this uncontroversial claim, and can appeal to it in defense against objections (see §III.1). ${ }^{19}$ But EV is

${ }^{18}$ Expanded contents are defined for predicates in the grammatical sense only, not the logical sense. As I note below, it is uncontroversial that some occurrences of 'good' are logically attributive. But this allows that 'good' can occur as a predicate in the grammatical sense. Geach agrees $(1956,34)$.

19 'Good' need not change in meaning when modifiers are added to 'Jane is good'. When this sentence is uttered during Jane's dance performance, its occurrence of 'good' can have the same semantic content that it has in the longer sentence 'Jane is good at dancing'. 
not committed to the controversial thesis that every occurrence of 'good' is logically attributive, or to the thesis that there is no concept or property of goodness-simpliciter (Geach 1956, 33-6; Thomson 2008, chs. 1-2). As far as EV is concerned, there might be some logically predicative occurrences of 'good' (e.g. (Pleasure is good'), and these occurrences might express good-simpliciter and represent the corresponding property.

II.3. Examples. Now consider three general categories of thick concepts that can be construed as expanded contents of thin terms.

First consider affective concepts like admirable, respectable, laughable, untrustworthy, and blameworthy. Along with Tappolet, we can assume affective concepts are thick $(2004,211)$. EV treats them as expanded contents of 'worthy' or 'unworthy', which take the following general forms — worthy-[of-something] or unworthy-[of-something]. For example, admirable is an expanded content of 'worthy', namely worthy-[ofadmiration]. And untrustworthy is an expanded content of 'unworthy', namely unworthy-[of-trust]. This is a natural view of affective concepts, and EV accounts for other thick concepts in a similar way.

Second, consider thick concepts like integrity, faithful, courageous, loyal, cowardly, betrayal, and perfidious. These will be called commitment-concepts. A commitment concept is an expanded content of 'true' or 'untrue'. They have the following general forms - true-[to-something-in-some-way] or untrue-[tosomething-in-some-way]. For instance, courageous is an expanded content of 'true', something like true-[to-agood-cause-despite-risk]. And cowardly is an expanded content of 'untrue', something like untrue-[to-a-goodcause-because-of-risk].

And third, consider thick concepts like benevolent, kind, generous, munificent, malevolent, nasty, rude, brutal, and cruel. These will be called treatment-concepts. According to EV, treatment concepts are expanded contents of 'good' or 'bad'. And these expanded contents have the following general forms good-[to-someone-in-some-way] or bad-[to-someone-in-some-way]. For example, kind is an expanded content of 
'good', something like good-[to-someone-as-an-end]. And brutal is an expanded content of 'bad', something like bad-[to-someone-aggressively]. ${ }^{20}$ This account of brutal explains why the promise-breaking physician's act is not brutal — resetting the broken leg is not bad to anyone aggressively.

The promise-breaking physician was meant to illustrate the coincidental application of a thick concept's evaluative and non-evaluative contents. There's no reason to think coincidences could present problems for EV. Consider the account of brutal. The non-evaluative content to-someone-aggressively is the content of a modifier; it therefore cannot apply unless it's combined with the content of another expression. It's thus unclear how this non-evaluative content could obtain coincidentally with bad. Of course, it's possible to combine this non-evaluative content with some other concept-e.g. speaks-[tosomeone-aggressively]. And it could be a mere coincidence that this combined concept applies to the same person as bad. But this coincidence doesn't require the application of the concept bad-[to-someoneaggressively] (i.e. brutal). An actress may speak to someone aggressively, while displaying bad acting, but that doesn't mean she's being bad to someone aggressively. So, there's no reason to think EV has problems with coincidence.

The above analyses are merely provisional sketches aimed at illustrating the general resources of EV. These sketches may only be rough approximations of what would result from serious conceptual analysis, if EV were true. EV is not committed to these examples. Elstein and Hurka qualify their analyses in the same way $(2009,531)$. Any Separabilist would do the same.

Nevertheless, it's useful to see how one such analysis can be explained and briefly defended. Consider the analysis of kind as good-[to-someone-as-an-end]. As noted earlier, kind action requires that the

20 'Brutal' is ambiguous. We often speak of brutal criticism and brutal weather, where the adjective 'brutal' is synonymous with 'harsh'. But the concept analyzed in this paper is different, and is rather expressed by talk of brutal beatings, bombings, etc., where 'harsh' is not an apt synonym. Consider also the noun 'brutality' — we wouldn't say that cold weather and harsh criticisms are examples of brutality, but we would say this about beatings, bombings, etc. The concept analyzed in this paper corresponds to both the noun and the adjective. Finally, the ambiguity of 'brutal' is typically indicated in lexical entries, and is supported by ambiguity tests, such as the ellipsis test - the sentence 'His critiques are brutal, and so are his beatings' is anomalous, much like ‘John's license expired, and so did John'. 
act be good to someone. ${ }^{21}$ But there are many ways of being good to someone. On the present analysis, the relevant way is specified by the phrase 'as an end' — this phrase concerns the agent's intention. At the very least, an action is good to Mary as an end only if the agent intends to be good to Mary. So, an action isn't kind if it's good to someone purely by accident or as a side-effect. Furthermore, an action is good to Mary as an end only if the agent is not intending to be good to her merely as a means. Suppose I am intentionally good to Mary, but I have this intention solely because I desire to produce another end. In this case, I'm being good to her merely as a means, not as an end, and so am not acting kindly towards her. ${ }^{22}$ As indicated, kindness depends heavily on intention - in addition to being good to someone, one must intend to do so, and not merely as a means to another end. Oftentimes, we ascribe kindness when we presume the agent has this intention but rescind the label if we learn the intention was absent. ${ }^{23}$ The present account explains why.

Most likely this analysis will be criticized for being too strong - it appears to exclude intuitively kind acts from being kind. For example, one might intuit that it's possible to act kindly towards Mary by being good to her merely as a means, or as a side-effect. But this sort of intuition can be explained away. We may be inclined to call such acts 'kind' because denying their kindness would imply something falsethat the acts are unkind. This implication from 'not kind' to 'unkind' isn't an entailment, since many actions are neither kind nor unkind (e.g. opening a cabinet). It's rather a conversational implicature known as negative-strengthening. When a negation is combined with certain words, like 'happy', this combination conversationally implicates a stronger claim involving the word's antonym (Levinson 2000, 127ff). For instance, 'A is not happy' conversationally implicates that A is unhappy. And plausibly, 'A is not kind'

\footnotetext{
${ }^{21}$ Acceptance of this is required for full competence with kind. Failed attempts at being good to someone are not examples of kindness. If I try to be good to Mary, but fail, at best I've only tried to be kind to her.

${ }^{22}$ Mixed intentions are possible - I can be good to her as an end and as a means, provided I'm not intending to be good to her solely because of some other end.

${ }^{23}$ Refusing to rescind the label may be due to politeness or fear that the agent will revoke bestowed benefits. It may also be due to the pragmatic mechanism discussed next.
} 
conversationally implicates that A is unkind. Returning to the abovementioned acts, it's clear that these acts are not unkind, since they are good to Mary. So, our denial of kindness in these cases would have a false implicature. Our desire to avoid this implicature can mislead us into ascribing kindness to an act that lacks this feature.

The strategy just outlined can be used to defend other analyses that appear too strong. When negative-strengthening implicatures are false, they can mislead us into thinking the target thick concept applies when in fact it doesn't. In Kyle (2017, §6), I argue this happens regarding courage.

Unfortunately, I cannot explore all sample analyses here. And it's possible that some may turn out implausible upon closer inspection. In that case, we can hope to reformulate them. What if we're unable to state a plausible reformulation? In §III.3, I argue that this still wouldn't establish the falsity of EV.

II.4. General Features. All the above examples fall under one of three general categories - affective concepts, commitment concepts, and treatment concepts. These categories are not exhaustive. There could be other categories involving expanded contents like good-[for-someone], good-[at-something], good[with-something], good-[qua-K], true-[as-a-K], and so on. EV could also make use of other thin terms, such as 'obligated' and 'permitted'. EV can be extended well beyond three categories.

Indeed, EV may be an instance of a general phenomenon that holds for non-evaluative concepts. For example, the non-evaluative concept ripe is plausibly an expanded content of 'ready', something like ready-[to-use-and-consume]. It is not implausible that instances of EV have analogues among non-evaluative terms.

How are evaluative and non-evaluative contents combined within a thick concept? According to EV, this just is the relationship between a thin term's content (e.g. good) and the content of its modifiers (e.g. to-others). Unlike dependence views, EV explains this relationship without mentioning any dependence relations. 
EV's silence about dependence relations makes it distinct from any dependence view. As noted in $\S$ I, dependence views require every thick concept to contain a conceptual component that represents a dependence relation. EV does not require every thick concept to contain such a component. According to EV, a thick concept is simply an expanded content of a thin term; these expanded contents needn't contain dependence concepts. ${ }^{24} \mathrm{EV}$ is therefore not a dependence view.

To be clear, EV does not prohibit thick concepts from containing dependence concepts. Recall that cowardly was analyzed as untrue-[to-a-good-cause-because-of-risk] — the concept because is a dependence concept. So, a thin term's expanded contents can in principle contain dependence concepts. The difference is just that EV doesn't require this sort of analysis whereas dependence views do. On EV, the question of whether a thick concept contains a dependence concept is answerable only on a case-by-case basis, solely by reflecting on the content of that particular thick concept.

What if it turns out, upon reflection, that all plausible instances of EV involve dependence concepts, much like the analysis of cowardly? The first thing to note is that EV still wouldn't be a dependence view, because EV doesn't require this outcome whereas dependence views do require it. The second thing is that it's unreasonable to expect this outcome - i.e. there's no reason to think all plausible instances of EV will involve dependence concepts. One potential reason would be an argument for a dependence view; but we saw in $§$ that no such arguments work. Alternatively, we could argue in a piecemeal fashion: for each analysis that doesn't contain dependence terms, we could try to paraphrase it in a way that does contain such terms. For example, we could paraphrase 'bad to someone aggressively' as 'bad to someone because of one's aggressiveness'. Regardless of whether this particular paraphrase is accurate, we cannot assume this strategy will work in every case. This is because we cannot assume, from the outset, that every such paraphrase will express the same concept as the original phrase. Since

\footnotetext{
${ }^{24}$ If there's no dependence concept within the thin term's semantic content or the modifier's content, then there needn't be one in the thin term's expanded content either.
} 
dependence terms are extensionally relevant, the addition of dependence terms can change the extension of the whole expression, thereby making the paraphrase express a different concept from the original phrase. ${ }^{25}$ And, for all we know, the original phrase might express the target thick concept (e.g. brutal) while the paraphrase does not. So, although EV allows that some of its analyses will involve dependence concepts, there's no reason to expect that all of them will.

Despite its silence on dependence relations, EV allows that thick properties may depend and/or supervene upon non-evaluative properties. On EV, the claim that kindness depends/supervenes on the non-evaluative is equivalent to the claim that being-good-to-someone-as-an-end depends/supervenes on the non-evaluative. These claims are equally plausible, and they might even be conceptual truths, as far as EV is concerned. Conceptual truths of this sort do not entail a dependence view of thick concepts, as was shown in $\S$ I.

EV is also compatible with the view that thin evaluations can depend upon thick ones (Dancy 2004, 84). For example, it's plausible that an action's wrongness can depend upon its brutality. On EV, this amounts to saying that the act's wrongness depends on its being bad to someone aggressively — and the concept bad-[to-someone-aggressively] is a thick concept. So, the application of a thin concept can depend on the application of a thick one.

Some might worry that EV is not really a form of Separabilism. But this is a mistake. Notice that Inseparabilists cannot accept EV. EV requires that thick concepts are composed of thin ones. And this claim is not compatible with Inseparabilism (Roberts 2011, 518).

Of course, Separabilism is more than just the denial of Inseparabilism. It's also a reductive theory, which can be construed in two ways. Weak Separabilism merely reduces a thick concept to evaluative and non-evaluative contents that are more fundamental than the thick concept itself. Strong Separabilism

\footnotetext{
${ }^{25}$ Even if the two phrases are coextensive, they still may not express the same concept (e.g. 'water' and 'H2O').
} 
requires that these constituent contents be expressible without thick terms. What kind of Separabilism is EV? Consider the initial statement:

\section{Expansion View}

Thick concepts are expanded contents of thin terms.

This is only a form of Weak Separabilism, because it allows that the relevant expanded contents may only be expressible with (other) thick terms. For example, it allows us to analyze malevolent as bad-[to-otherswith-malice], even if 'malice' is a thick term. Weak Separabilism owes us an account of these embedded thick terms (e.g. Tappolet 2004, 217-18). Fortunately, EV can be transformed into Strong Separabilism merely by adding another claim:

\section{Supplement}

And these expanded contents are expressible without thick terms, at least in principle.

If 'malice' is thick, then, according to Supplement, we should be able to modify the above analysis of malevolent so that 'malice' is not used to express the analysans (e.g. bad-[to-others-with-intent-to-inflictunnecessary-harm]). Since Strong Separabilism is harder to defend, let's assume EV is combined with Supplement. There's no guarantee that this form of Strong Separabilism is true, but we can examine whether there's reason to think it's false. §III.3 discusses various objections.

Even though EV requires that thin concepts are constituent parts of thick concepts, it does not require thin centralism — the view that thin concepts are conceptually prior to thick ones (Hurley 1989, 11). On the most common interpretation, thin centralism requires that it be possible to grasp a thin concept without grasping any thick concepts. But we can deny this requirement, as far as EV is concerned. In particular, EV allows that thin concepts like good cannot be grasped without grasping some specific concept such as good-[to-someone], good-[at-dancing], good-[with-children], etc. ${ }^{26}$ EV also allows that these specific concepts are thick, since they are expanded contents of 'good'. So, as far as EV is concerned, it

\footnotetext{
${ }^{26}$ This view of good appears in Thomson (2008) and Geach (1956). It does not entail their controversial claim that there's no such thing as good-simpliciter, since good-simpliciter might be an abstraction from the specific concepts.
} 
might be impossible to grasp good without grasping some thick concept or other. EV therefore does not require thin centralism.

Some Inseparabilists understand the relation between thick and thin as analogous to the determinate-determinable relation (e.g. Harcourt and Thomas 2013, 25). This idea is also compatible with EV. If there are any determinates of good, then the following expanded contents would clearly be among them: good-[to-someone], good-[at-dancing], etc. And, again, EV allows that these concepts are thick. So, it allows that thick concepts might be determinates of some determinable thin concept.

\section{Objections}

III.1. Unwanted Entailments. If EV were true, wouldn't thick concepts have unwanted entailments? Take the account of kind as good-[to-someone-as-an-end]. One might worry that this account entails that kindness is always a good thing - a claim that has obvious counterexamples. Imagine a Nazi sympathizer who makes tea for a weary Nazi soldier in order to revitalize him. The sympathizer's action is not a good thing, but we can assume it's kind.

Is this counterexample a problem for the analysis of kind as good-[to-someone-as-an-end]? No. It would only be a problem if we assumed the following premise - that being good to someone as an end is always a good thing. But the sympathizer case is equally a counterexample to this premise; it's easy to imagine that the sympathizer is being good to the Nazi as an end. Furthermore, there's no reason to assume the above premise would be true. As noted earlier, it's highly plausible that some good + modifier phrases are logically attributive. We thus have no reason to assume that every sentence of the form 'A is good +modifier' entails that A is a good thing. At best, this sort of entailment holds on a case-by-case basis. And the sympathizer example reveals that it does not hold in the present case - 'A is good to someone as an 
end' does not entail that A is a good thing. Thus, the analysis of kind does not require that kindness is always a good thing. ${ }^{27}$

III.2. Variability and Ambivalence. Plausibly, the evaluations of thick terms can exhibit two unique features — variability and ambivalence. Does EV allow thick terms to have these features?

Roughly, an evaluative expression is variable if it can be used to evaluate positively in some contexts but negatively in others (Väyrynen 2011,3). Examples include 'frugal' and 'tidy'. Since EV accounts for thick terms with seemingly invariable expressions, like 'good', one might think EV requires that thick terms are also invariable. But this is a mistake. EV is consistent with the variability of thick terms. ${ }^{28}$ Notice that variability can be exhibited by the modifier phrases employed by EV. Although expressions of the form 'good to $\mathrm{X}$ ' and 'true to $\mathrm{X}$ ' are normally positive, they can be used negatively. If we assume that $\mathrm{X}$ is a tyrant, you could rightly criticize me as being good to $\mathrm{X}$ or true to $\mathrm{X}$. Or consider expressions of the form 'worthy of X'. The phrase 'worthy of laughter' is positive when applied to something intended to provoke laughter (e.g. a joke), but negative when applied to something not so intended (e.g. an offer to buy your home). So, the modifier phrases employed by EV can exhibit variability.

Thick terms also display ambivalence. An ambivalent expression is, roughly, an evaluative expression that can sometimes be used to evaluate without a clear positive or negative valence. Potential examples include 'suave' and 'macabre' (Kirchin 2013, 75). But ambivalence can also be exhibited by the modifier phrases employed by EV. Consider the expression 'worthy of intrigue'. This expression has

\footnotetext{
${ }^{27}$ One may worry that this approach excludes kind from being a moral or ethical concept. But this worry arises from the sympathizer case alone, regardless of EV. If moral/ethical concepts must entail good-thing, then the sympathizer case shows that kind is not a moral/ethical concept, regardless of EV. Of course, EV's analysis of kind is not excluded by other accounts of moral/ethical concepts - e.g. involving harms and benefits, other-regardingness, impartiality, universalizability, etc.

${ }^{28}$ Linguistic explanations of variability cannot be discussed here. For this, see Väyrynen (2011). Väyrynen also shows that the variability of comparative constructions (e.g. 'too tidy') is not due to the thick term itself, but to the comparatives. This discussion focuses solely on the variability of expressions in their positive forms.
} 
clearly positive uses, as when it's applied to wine. It also has clearly negative uses-Thomas Jefferson once criticized a life-long presidential office as being "worthy of intrigue."29 But it can also be used ambivalently. Suppose I'm unsure about whether a certain financial opportunity is a scam or a smart investment. In this case, I might say it's worthy of intrigue, without providing a clear positive or negative assessment. What about expressions of the form 'good to X' and 'true to X'? These too can be used ambivalently, provided it's unclear whether we should have a positive or negative view about X. In short, the modifier phrases employed by EV can also exhibit ambivalence.

Some take the ambivalence of evaluative expressions to support a claim about evaluative contentnamely "that evaluative content itself can come in more varieties than pro and con.” According to Simon Kirchin, this claim conflicts with Separabilism (2013, 74-5). However, EV is a Separabilist view that does not assume thick concepts must be either positive or negative. ${ }^{30}$ To see why, let's assume that 'worthy' always expresses a positive evaluative concept when used by itself. This assumption doesn't entail that all expanded contents of 'worthy' are positive_—worthy-[of-blame] isn't positive. It also doesn't entail that all expanded contents of 'worthy' are negative — worthy-[of-admiration] isn't negative. And without the initial assumption, there's no reason why all expanded contents of 'worthy' must have either a positive or a negative valence. Since expanded contents of 'worthy' are thick concepts, on EV, we therefore have no reason to claim that every thick concept must have either a positive or negative valence. To put this in another way: it's clear that a modifier's content can reverse a thin concept's evaluative valence when the two are combined — worthy-[of-blame] is just one example. Why then couldn't a modifier's content alter that evaluation so that it's neither pro nor con? EV doesn't preclude this from happening.

\footnotetext{
${ }^{29}$ See <http://www.let.rug.nl/usa/presidents/thomas-jefferson/letters-of-thomas-jefferson/jefl65.php>, accessed $4 / 3 / 2019$.

${ }^{30}$ We do need to explain how a content can be evaluative without being positive or negative. Assume this can be done for present purposes.
} 
III.3. Unsatisfactory Analyses. The commonest objection against EV targets the sample analyses aimed at illustrating it. There are at least three ways to frame this objection.

First, one could object that these sample analyses sometimes feature thin concepts where nonevaluative concepts should appear. In the analysis of courageous as true-[to-a-good-cause-despite-risk], the thin concept good appears in the extra content. However, it's a mistake to assume that the extra content cannot contain thin concepts. Elstein and Hurka allow for additional thin concepts to be "embedded" in the nonevaluative contents of thick concepts $(2009,526)$. EV allows for this too. There's no reason why Separabilists should be restricted to citing only one thin concept, rather two or three or many more.

Second, one could worry that these analyses sometimes contain thick terms in the analysans, and so do not satisfy Strong Separabilism. For example, recall that brutal was analyzed as bad-[to-someoneaggressively]; it might be objected that 'aggressive' is a thick term. However, 'aggressive' is not a thick term by our account, because the concept aggressive fails the necessary condition for thickness. One need not evince a deficient grasp of aggressive if one thinks that aggressive workouts are not wrong, or not bad in any way, etc. So, aggressive is not thick.

The term 'aggressive' might be thick in a broader sense that allows pragmatically-evaluative terms to be thick. That is, 'aggressive' might have an evaluation that's not semantically encoded but is associated via some pragmatic mechanism (e.g. speaker meaning). But this would not help the objection. The Strong Separabilist version of EV only needs to preclude semantically-evaluative thick terms from appearing in the analysans, because semantically-evaluative thick terms are the only terms EV seeks to explain.

But let's suppose for the sake of argument that 'aggressive' is a semantically-evaluative thick term. What are the options? Proponents of EV could maintain Strong Separabilism by claiming that 'aggressive' is not needed to express a correct analysis of brutal. Perhaps another term can be used instead, such as 'forceful'. Or they could propose that aggressive is itself identical to an expanded content of a thin term, and then substitute this expanded content for aggressive within the account of brutal. So, there are options, 
although none are necessary in the present case, since 'aggressive' is not a semantically-evaluative thick term.

The third objection claims that EV must yield incorrect analyses, unless the target thick concepts are employed somewhere in the extra content, which would render them circular. Initially, we can assume this objection relies on counterexamples. Let's suppose there's a successful counterexample against the analysis of courageous as true-[to-a-good-cause-despite-risk].

This supposition doesn't by itself support the objector's claim. For all we know, it might be possible to state a correct non-circular analysis of courageous, in accord with EV, if we simply reformulate the one provided. To support the objector's claim, we must also suppose that our language lacks the resources to state a plausible reformulation, unless courageous appears in the extra content. But even this supposition doesn't entail the objector's claim, since it doesn't exclude the possibility of us introducing new expressions into our language that would help us state a correct non-circular analysis. Imagine that we can introduce a modifying expression ' $\varphi$ ' such that courageous is identical to the semantic content of 'true $\varphi$ '. In this case, courageous would satisfy EV, despite our present suppositions. To support the objector's claim, it must be argued that ' $\varphi$ ' could not be introduced.

One such argument is unsuccessful. This argument correctly notes that ' $\varphi$ ' must be graspable independently of courageous (otherwise the analysis would be circular). But the argument alleges that ' $\varphi$ ' cannot be grasped independently of courageous. And there's no reason to accept this last claim. Initially, one might accept it because courageous was used to introduce ' $\varphi$ ' in the above paragraph. But this is merely a contingent etymological fact about the origin of ' $\varphi$ ' in our present context; and we have no reason to think such a word couldn't be introduced in a way that's not parasitic upon courageous — perhaps a linguistic community will happen upon an expression like ' $\varphi$ ' without even possessing courageous. Furthermore, this etymological fact doesn't entail that it's impossible to grasp ' $\varphi$ ' independently of courageous. To borrow 
Elijah Millgram's example, the concept insect was used to introduce 'debugging', a computer programmer's term. But it's possible to understand 'debugging' without even possessing insect (1995, 358-9).

The hypothesis that we could have an expression such as ' $\varphi$ ' may seem reminiscent of Hare's controversial claim that we "could have" an "evaluatively neutral word" that's coextensive with 'courageous' (1963, 189). However, we can reject Hare's claim while still allowing that ' $\varphi$ ' could be introduced. Hare's imagined word is different from ' $\varphi$ ' in three ways. (i) Hare envisions the introduction of a single word, whereas ' $\varphi$ ' could be a complex expression. (ii) Hare's imagined word is wholly non-evaluative, but ' $\varphi$ ' could be partly evaluative. Since ' $\varphi$ ' might be complex, it could contain thin terms. In this case, ' $\varphi$ ' would be partly evaluative, and the overall analysis would not compromise Strong Separabilism. And (iii) Hare's envisioned word is supposed to be coextensive with 'courageous', whereas ' $\varphi$ ' is not. Only 'true $\varphi$ ' would be coextensive with 'courageous', but not ' $\varphi$ ' itself. So, the two expressions are importantly different. And the arguments against Hare's view always target his claims in (ii) and (iii). Since these claims don't apply to ' $\varphi$ ', the counterarguments are irrelevant in the present context. ${ }^{31}$ It's thus unclear why we must deny that an expression like ' $\varphi$ ' could be introduced. So far, we have no support for the objector's claim that EV cannot supply correct non-circular analyses.

Another way to support the objector's claim would be to argue directly for Inseparabilism, rather than rely on counterexamples. Inseparabilism is often supported by considerations such as the denial of thin centralism (Williams 1985, 146), the rejection of dependence views (Dancy 1995, 275), an appeal to the determinable/determinate relation (Harcourt and Thomas 2013, 24-5), the variability of thick terms (Dancy 1995, 276), the ambivalence of thick concepts (Kirchin 2013, 75), the denial of Disentangling (Dancy 1995, 276), and the denial of Shapefulness (McDowell 1981, 202). But these considerations do not

\footnotetext{
${ }^{31}$ These counterarguments involve the shapelessness hypothesis and outrunning data, both of which are discussed in $\S I V$. It's argued that EV is consistent with both.
} 
support Inseparabilism over EV. We've already seen that EV is consistent with them all, except the last two. And in the next section, we will see that even non-cognitivist proponents of EV can reasonably deny Disentangling and Shapefulness. So, these considerations do not support Inseparabilism over EV, and therefore cannot support the objector's claim.

\section{Anti-Disentangling}

IV.1. Argument. The Anti-Disentangling Argument can now be addressed. ${ }^{32}$ This argument will be advanced with regard to the thick concept kind, although it could be formulated for any thick concept that plausibly represents a property.

Let's suppose kind represents a property and is constituted by good along with certain nonevaluative contents, as Separabilists may hold. This view is vulnerable to the Anti-Disentangling Argument if it entails

Disentangling: The non-evaluative content of kind fully determines what property is represented by kind, while good plays no role in determining this.

According to Bernard Williams (1985, 141), Disentangling entails

Shapefulness: There could be a non-evaluative concept that represents the same property as kind.

The Anti-Disentangling Argument challenges both Shapefulness and Disentangling. It states: If Shapefulness is true then an outsider who does not share the insider's evaluative perspective could know the extension of 'kind' (i.e. by observing the property represented by its non-evaluative content). But an outsider surely could not achieve this - the extension of 'kind' cannot be determined without grasping the insiders' evaluative perspective (Williams 1985, 141; Putnam 2002, 37-8; McNaughton 1988, 60-1). Therefore, Shapefulness is false, and so is Disentangling, which entails Shapefulness.

\footnotetext{
${ }^{32}$ I only explain how the argument is typically construed, whether or not this adequately captures McDowell's original
} version. 
This paper takes no stand on the truth or falsity of Disentangling or Shapefulness. It rather focuses on whether EV requires anyone to accept these controversial claims. In §IV.3-IV.4, it's argued that there's no reason to think EV requires anyone to accept Disentangling. In $\S I V .5$, a similar claim is advanced regarding Shapefulness. First, however, we must clarify what view is thought to entail Disentangling, and how the inference is supposed to go.

IV.2. Non-Cognitivism. A view that's commonly thought to entail Disentangling is a particular form of non-cognitivism that accepts Separabilism and allows thick concepts to represent properties (Williams 1985, 141-2; Putnam 2002, 38-9). Out of all views compatible with EV, this form of non-cognitivism is most vulnerable to the Anti-Disentangling Argument. ${ }^{33}$ So, it will be assumed that if this view can escape the argument by accepting EV, then so could cognitivist views.

To illustrate this view, let's assume a non-cognitivist accepts

Representation: The concept kind represents a property.

Initially, one might think non-cognitivism is inconsistent with Representation, because kind is an evaluative concept, and non-cognitivists hold that evaluative concepts cannot represent properties - an apparent implication of their distinction between description and evaluation.

But proponents of the Anti-Disentangling Argument grant that non-cognitivists can avoid this problem if they accept Separabilism (Putnam 2002, 36; Roberts 2013, 679). Non-cognitivists can claim that kind is only evaluative in the sense that it's partly constituted by a thin concept. For instance, they can accept

Kind-Separabilism: The concept kind is partly constituted by good along with non-evaluative contents.

${ }^{33}$ Mackie is also targeted by the argument, although he's interpreted as holding that thick concepts are "not ethical or normative concepts at all” (Putnam 2002, 36). Thusly interpreted, Mackie's view is inconsistent with EV, and will not be discussed here. 
And they can maintain their distinction between description and evaluation by claiming that thin evaluative concepts cannot represent properties. This would include

Non-Descriptivism: The concept good is incapable of representing a property.

No similar claim would hold for thick concepts like kind. So, if non-cognitivists accept Kind-Separabilism and Non-Descriptivism, they can explain their descriptive/evaluative distinction in a way that's consistent with Representation.

However, it is the combination of these three claims - Representation, Kind-Separabilism, and Non-Descriptivism - that's the target of the Anti-Disentangling Argument (Roberts 2013, 679).

Henceforth, any view that accepts all three claims will be called 'target-non-cognitivism'.

One might initially think target-non-cognitivism entails Disentangling, but this inference is not valid unless target-non-cognitivism is supplemented with an additional claim. To be sure, target-noncognitivism holds that good cannot represent a property; but this does not automatically entail the crucial claim in Disentangling - that good cannot play a role in determining what property is represented by another concept (e.g. kind). So, an additional claim is needed to make the inference valid.

What's the additional claim? One possibility is offered by Debbie Roberts, who observes that noncognitivists often accept universalizability. Roberts states universalizability as follows:

(U1) If I judge that $\mathrm{x}$ is "good in virtue of being T" (where ' $\mathrm{T}$ ' is non-evaluative), I'm "logically bound" to judge the same for any y that I judge to be T $(2011,498)$.

Assuming kind is identical to good-in-virtue-of-being- $T$, it appears that $T$ would completely determine the speaker's use of 'kind'.

As forecasted, Roberts is here assuming Separabilists should accept a dependence view. But if kind is a treatment concept, in accord with EV, it needn't be identical to any concept like good-in-virtue-of-beingT. It's rather identical to something like good-[to-someone-as-an-end]. In this case, (U1) might be true, but it would imply nothing about the proper usage of 'kind'. 
Furthermore, there's no feasible way of revising (U1) to accommodate the view that kind is identical to good-[to-someone-as-an-end]. Here's one attempt:

(U2) If I judge that $\mathrm{x}$ is good to someone as an end, I'm logically bound to judge the same for any y that I judge to be someone who is treated as an end. ${ }^{34}$

(U2) is false. Suppose I judge that a woman is good to someone as an end, and I also judge that her abusive spouse is the person she is treating as an end. Clearly, I'm not thereby required to judge that her abusive spouse is also good to someone as an end. Another revision goes like this:

(U3) If I judge that $\mathrm{x}$ is good to someone as an end, I'm logically bound to judge the same for any $y$ that's non-evaluatively similar to $\mathrm{x}$.

Although (U3) is plausible, it fails to support Disentangling. At a minimum, the non-evaluative similarity between $\mathrm{x}$ and $\mathrm{y}$ guarantees that $\mathrm{y}$ falls under the bracketed content - [to-someone-as-an-end] — in the same way as $\mathrm{x}$. In other words, it guarantees that $\mathrm{y}$ also treats someone as an end. But one way for $\mathrm{y}$ to treat someone as an end is for $\mathrm{y}$ to be bad to someone as an end. ${ }^{35}$ So, the bracketed non-evaluative content does not by itself require me to judge that y is good to someone as an end, even if I judge this for x. Of course, the non-evaluative similarity between $\mathrm{x}$ and $\mathrm{y}$ involves other features too-features that aren't encoded in the bracketed non-evaluative content, but which may entail that y is good to someone as an end. But here we're allowing features that aren't encoded in the bracketed non-evaluative content to play a role in determining the application of the whole concept good-[to-someone-as-an-end] (i.e. kind). We thus lose our support for Disentangling. In short, universalizability does not force Disentangling upon target-noncognitivists who accept EV.

\footnotetext{
${ }^{34}$ It's not immediately clear what sorts of individuals can be recipients of kindness - e.g. they cannot be inanimate objects, but what about non-sentient beings (e.g. plants)? Since this makes no difference to my present argument, I leave the question open.

${ }^{35}$ For our purposes, 'treating someone as an end' is non-evaluative, since it merely expresses the bracketed nonevaluative content. As clarified in §II.3, the phrase simply means that the treatment is intentional and isn't solely aimed at some further end - in this sense, sadistic acts often treat someone as an end. Clearly this is different from the Kantian slogan (i.e. treating people as ends in themselves).
} 
But the inference from target-non-cognitivism to Disentangling could be supplemented with a different claim. In explaining the Anti-Disentangling Argument, Stephan Burton writes

If that distinction [between description and evaluation] is to be maintained, no such apparently cognitive role can be allowed for the purely evaluative component of thick evaluative concepts.

By 'apparently cognitive role', Burton means the role that constituent thin concepts would play if they determined "what falls under some thick evaluative concept" $(1992,30)$. So, the above passage can be interpreted as follows: if thin concepts are incapable of representing properties (as required by the description-evaluation distinction), they cannot play a role in determining what property is represented by thick concepts that contain them. The relevant instance of this is as follows:

Neglected Premise: If good is incapable of representing a property, then good cannot play a role in determining what property is represented by concepts that contain it.

It appears that target-non-cognitivism and Neglected Premise jointly entail Disentangling. And, in contrast to Roberts' approach, Neglected Premise would not be rendered irrelevant if target-non-cognitivists accepted EV. It will thus be assumed that Neglected Premise is an integral part of the inference.

Neglected Premise is initially plausible. ${ }^{36}$ But it will be argued that, if EV is true of kind, then target-non-cognitivists have no reason to accept Neglected Premise. Even if good is incapable of representing a property, there's no reason why good cannot play a role in determining what property is represented by expanded contents of 'good' (e.g. kind). The precedence for this idea comes from the notion of a semantically incomplete predicate.

36 It's doubtful that Blackburn's 'fat $\downarrow$ ' is problematic for claims like Neglected Premise. See Väyrynen $(2013,163-4)$ and Dancy $(1995,271)$. 
IV.3. Incompleteness. Incompleteness is arguably a feature of both sentences and predicates. ${ }^{37}$ This section focuses on incomplete predicates, and distinguishes two forms of incompleteness - contextual and semantic.

According to Zoltan Szabó, an incomplete predicate is one that "is associated with a set of individuals [i.e. an extension] only if additional information is provided” (2001, 133). Since a predicate cannot represent a property unless the predicate has an extension, we can spell out Szabó's account as follows: an incomplete predicate is one that represents a property only if additional information is supplied. By 'additional information' Szabó means information that's not solely specified by the sentence containing the incomplete predicate, but which would count as part of the predicate's semantic content $(2001,34)$.

Incomplete predicates are arguably widespread, possibly including evaluative adjectives (e.g. 'good'), color adjectives (e.g. 'green'), and others (e.g. 'late'). For simplicity, let's focus on the nonevaluative predicates in (4) and (5) below, which are common examples:

(4) Tipper is ready.

(5) Hughes is tall.

What property, if any, is represented by 'ready' in (4)? There are indefinitely many candidates - e.g. the property of being ready to work, ready to dance, ready to eat, etc. But (4) fails to indicate which property is had by Tipper. It appears to need additional information that would specify an event for which Tipper is ready. Likewise, there are indefinitely many properties corresponding to 'tall' in (5) - e.g. the property of being tall for a basketball player, tall for a jockey, tall for a human, etc. And (5) fails to indicate which one is had by Hughes. (5) appears to need information that would specify a comparison class.

\footnotetext{
${ }^{37}$ Incomplete sentences are appealed to by Bach (2012, 163-4) and Soames (2008, 456; 2010, 155-6). Adherents of incomplete predicates include Szabó (2001) and Finlay $(2014,20)$.
} 
In the absence of additional information, there may be no suitable property that could be represented by the predicates in (4) and (5). Herman Cappelen and Ernie Lepore $(2005,166)$ hold that the occurrence of 'ready' in (4) picks out

$\mathrm{R}$ : the property of being ready.

But their view appears to entail a contradiction (Borg 2007, 350-1). Cappelen and Lepore agree that if Tipper is ready to eat then she has R $(2005,167)$. Similarly, Tipper should lack R if she's not ready for an exam. But it's possible that Tipper is both ready to eat and not ready for an exam. So, Tipper has $\mathrm{R}$ and lacks R. To avoid such contradictions, Emma Borg replaces R with an existentially-quantified property (2007, 351):

$\mathrm{R} *$ : the property of being ready for something.

The trouble is that everything apparently has $\mathrm{R}^{*}$. As long as Tipper is ready for her next breath, she has $\mathrm{R}^{*}$, which means, oddly enough, that (4) is true throughout Tipper's entire life. Similar problems arise for (5). These problems merely serve to illustrate why philosophers appeal to incomplete predicates; nothing in our discussion hangs on them. ${ }^{38}$

Assuming there are incomplete predicates, we can distinguish two ways in which a predicate might be incomplete. Recall the general account of an incomplete predicate-a predicate that represents a property only if supplemented with additional information that would be part of its semantic content. One option is to hold that the additional information can be provided. For example, one might hold that the context of utterance supplies such information (Szabó 2001, 133-4). On this view, the incomplete predicate would only be contextually incomplete. Another option, however, is to deny that such additional information can be provided. From this, it follows that the incomplete predicate fails to represent a

${ }^{38}$ And there are other reasons for ascribing incompleteness to a given predicate. See Szabó (2001). 
property (Bach 2012, 163-4; Soames 2008, 456; 2010, 155-6). ${ }^{39}$ On this view, the incomplete predicate is semantically incomplete.

Our sole focus will be on semantic incompleteness. If an incomplete predicate is semantically incomplete, it doesn't represent a property at all. The needed additional information is not determined by anything in the domain of semantics, not even by context. Kent Bach, for example, denies that context can determine any additional information that would be part of the semantic content of the predicates in (4) and (5). He thereby denies that these predicates can represent properties (2006, 438-9; 2012, 161-5).

Why can't context determine semantic contents for incomplete predicates? For Bach, the only kind of context that can determine semantic contents for an expression is "narrow context," which includes objective facts, like the speaker's identity and time of utterance, but excludes the speaker's intention. As such, narrow context can determine the semantic contents of automatic indexicals (e.g. 'I' and 'today') which refer independently of the speaker's intention. But sentences like (4) contain no automatic indexicals. And there appear to be no objective facts that could determine the property of being ready to eat, rather than ready to dance, as the semantic content of (4). Perhaps one of these properties is what the speaker intends to ascribe. But according to Bach, the speaker's intention only determines "what the speaker means, not the [semantic] contents of expressions the speaker uses" $(2012,166)$.

What are the semantic contents of semantically incomplete predicates? Bach is silent on this question, but others call them "pro-concepts". Pro-concepts are semantic contents that cannot represent properties or individuals, or act as constituents of thought, unless they're "fleshed out" with additional content (Wilson 2011, 15-6).

It's crucial to note that the semantic incompleteness of a predicate doesn't entail that all augmented versions of the predicate fail to represent properties. Bach holds that the occurrence of 'tall' in (5) is

\footnotetext{
${ }^{39}$ Bach and Soames are primarily concerned with semantically incomplete sentences, not predicates. I assume their claims apply analogously to predicates.
} 
semantically incomplete and thus cannot represent a property. But he also holds that there are augmented versions of this predicate, like 'tall for a jockey', that do represent properties $(2012,171)$. This augmented version provides additional information that the truncated version fails to provide. But notice that the augmented predicate — 'tall for a jockey' — is the result of adding a modifier to 'tall'. So, the semantic content of this augmented version is an expanded content of 'tall'. Thus, Bach's view entails that some predicates fail to represent properties even though they have expanded contents that do not thusly fail.

For argument's sake, let's suppose Bach is right that tall-[for-a-jockey] represents a property even though tall does not. This entails that tall must play a role in determining what property is represented by tall-[for-a-jockey]. To see why, assume for reductio that tall plays no role in determining what property is represented by tall-[for-a-jockey]. In this case, a similar claim would hold for short - that is, short plays no role in determining what property is represented by short-[for-a-jockey]. And these two claims entail an absurdity — that tall-[for-a-jockey] represents the same property as short-[for-a-jockey]. After all, the only difference between these two expanded contents is that one contains tall while the other contains short. Thus, assuming Bach is right, we must conclude that tall plays a role in determining what property is represented by tall-[for-a-jockey], even if tall doesn't represent a property by itself.

We now have the makings of a counterexample to Neglected Premise. The above considerations about semantic incompleteness entail

\section{$\underline{\text { Bach's Schema }}$}

There is a predicate $\mathrm{P}$ such that $\mathrm{P}$ 's semantic content (i) does not represent a property but (ii) does play a role in determining what property is represented by an expanded content of $\mathrm{P}$.

It should be clear that, if 'good' satisfies Bach's Schema, then Neglected Premise is false.

This paper, however, does not establish the controversial claim that 'good' actually satisfies Bach's Schema. In the next section, I merely argue that target-non-cognitivists have no reason to deny that 'good' satisfies Bach's Schema (regardless of whether they have reason to accept it). This modest conclusion is enough to show that target-non-cognitivists are not required to accept Neglected Premise or Disentangling. 
To be clear, the argument for this modest conclusion doesn't rely on an analogy between 'good' and 'ready' or 'tall'. To see why, we can suppose, contrary to Bach, that 'ready' and 'tall' do not actually satisfy Bach’s Schema. This supposition destroys any putative analogy. But, as we'll see, the supposition leaves the arguments in the next section completely intact; it has no bearing on whether target-noncognitivists can reasonably claim that 'good' satisfies Bach's Schema. So, my challenge to Neglected Premise will not rely (even implicitly) on an analogy between 'good' and 'ready' or 'tall'. The above discussion of semantic incompleteness is only meant to show that there's an independent line of thought that rejects claims like Neglected Premise. Whether non-cognitivists can reject Neglected Premise is another matter that will be treated separately.

The next section argues that target-non-cognitivists have no reason to deny that 'good' satisfies Bach's Schema. It's important to note that target-non-cognitivists are already committed to the view that 'good' satisfies clause (i) of Bach's Schema. This is due to their acceptance of Non-Descriptivism. So, for our purposes, we can ignore any arguments denying that 'good' satisfies (i). These would be separate arguments against Non-Descriptivism, and the Anti-Disentangling Argument is not supposed to depend on any such arguments. We will plainly assume that 'good' satisfies (i). The focus will be on whether targetnon-cognitivists can reasonably claim that 'good' also satisfies (ii).

IV.4. Could 'Good' Satisfy (ii)? There are various ways to argue that target-non-cognitivists should deny that 'good' satisfies (ii). Seven such arguments, labeled (A)-(G), will be rejected below.

Argument (A): No predicates satisfy both (i) and (ii) of Bach's Schema. So, target-non-cognitivists must deny that 'good' satisfies (ii), since they're already committed to its satisfaction of (i). The primary argument for this claim — that no predicates satisfy (i) and (ii) — comes from Cappelen and Lepore (2005, ch.5). They argue that the intuitive support for (i) equally suggests that (ii) is unsatisfied. For example, many people intuit that the occurrence of 'ready' in (4) needs additional information specifying an event for 
which Tipper is ready_-let's call this an incompleteness intuition. Incompleteness intuitions initially suggest that truncated versions of 'ready' are semantically incomplete, and thereby satisfy (i). But one may also have incompleteness intuitions about augmented versions, such as 'ready for school'. Here, we also need additional information — we need to know whether Tipper is ready to begin a school-day or a schoolyear, etc. We could further augment the expression to specify such information. But, according to Cappelen and Lepore, incompleteness intuitions could be adduced for any augmented version..$^{40}$ Thus, if we trust incompleteness intuitions in thinking (i) is satisfied, we should also think that augmented versions don't represent properties, in which case (ii) is unsatisfied.

If successful, this objection would not establish the desired conclusion that no predicates satisfy Bach's Schema. It would only show that incompleteness intuitions aren't good reasons for thinking a predicate satisfies Bach's Schema. And we can easily grant this conclusion. That is, we can grant that target-non-cognitivists cannot consistently rely on incompleteness intuitions in thinking that 'good' satisfies (i), unless they also think it fails to satisfy (ii). But this conclusion is irrelevant, since target-non-cognitivists have never relied on incompleteness intuitions in claiming that 'good' satisfies (i). Their reasons are entirely different, and are discussed under the next argument.

Argument (B): Target-non-cognitivists cannot accept that 'good' satisfies (ii), because they must hold that every expanded content of 'good' fails to represent a property. But why must they hold this? The answer is unclear. Non-cognitivists can, and often do, restrict their views by only denying that there are properties represented by select evaluative concepts, like right, ought, rational, and good. ${ }^{41}$ Allan Gibbard, for example, restricts his view to the concept rational (1990, 8). Moreover, as noted earlier, target-noncognitivists are already committed to a similar restriction - they deny that good represents a property but

\footnotetext{
${ }^{40}$ Bach denies this claim $(2012,177-8)$.

${ }^{41}$ Ayer is an exception — see Argument (D).
} 
allow kind to represent a property. These restricted forms of non-cognitivism do not automatically prohibit expanded contents of 'good' from representing properties.

To be sure, the claim that good is incapable of representing a property is typically motivated by considerations such as Moore's open-question argument, Mackie's queerness argument, motivational internalism, and supervenience. Do these arguments also imply that expanded contents of 'good' fail to represent properties? Without going into detail, suffice it to say that target-non-cognitivists must hold that these arguments are unpersuasive with regard to good-[to-someone-as-an-end], even if they are persuasive for good. After all, they must hold that such arguments do not support the claim that kind fails to represent a property, since they accept Representation. And there's no reason to treat kind any differently from good[to-someone-as-an-end], when it comes to these arguments. So, it seems that a principled non-cognitivist who accepts Representation, despite the above arguments, is not precluded from holding that good-[tosomeone-as-an-end] represents a property.

Argument (C): If 'good' satisfies (ii) then good plays a role in determining what property is represented by another concept $C$ that contains good. But if good plays such a role, then there exists an evaluative property - the property represented by $C$. And non-cognitivists cannot allow evaluative properties.

However, the claim that good helps determine what property is represented by $C$ doesn't entail that there exists an evaluative property. All it entails is that the property actually represented by $C$ is different from what would have been represented if good was not a constituent of $C$. The mere fact that $C$ would have represented a different property doesn't entail that there are evaluative properties.

Of course, one could supplement Argument (C) with an additional claim: all properties represented by evaluative concepts are thereby evaluative properties. This would guarantee that the property represented by $C$ is evaluative. But this additional claim is incompatible with target-noncognitivism, regardless of whether 'good' satisfies (ii). Notice that this claim would commit target-non- 
cognitivism to the existence of evaluative properties merely by virtue of Representation, since kind is an evaluative concept that represents a property. So, there's an independent reason for why target-noncognitivists must reject the additional claim; it therefore cannot provide them with reason to deny that 'good' satisfies (ii). ${ }^{42}$

Argument (D): Bach's Schema was supported by the need to avoid an absurdity — that tall-[for-ajockey] represents the same property as short-[for-a-jockey]. But target-non-cognitivists should embrace the alleged absurdity when it comes to good. They should admit that good-[to-someone as-an-end] represents the same property as bad-[to-someone as-an-end] — both concepts represent a non-evaluative property (e.g. the property of treating someone as an end).

It's true that some non-cognitivists embrace this approach. A.J. Ayer, for instance, holds that “[t]he presence of an ethical symbol in a proposition adds nothing to its factual content.” Let's call this Ayer's Commitment. Ayer's Commitment implies that good-[to-someone-as-an-end] represents the same property as bad-[to-someone-as-an-end], since good and bad add nothing to factual content. ${ }^{43}$ But the question is whether there's any reason to accept Ayer's Commitment. One reason might be Argument (C) from above, which has been rejected. Ayer himself has a different reason-he claims that Ayer's Commitment explains the supposed fact that good is "irreducible to empirical concepts" (1946, 106-7). The trouble is that Non-Descriptivism by itself explains this supposed fact (since empirical concepts are capable of representing properties). So, it's unclear why Ayer's Commitment should be accepted in addition to NonDescriptivism.

It's also worth noting that Ayer is not a target-non-cognitivist. He extends his non-cognitivism to "all normative ethical symbols," and thereby denies that there are properties represented by 'virtue',

${ }^{42}$ Broadly speaking, target-non-cognitivists must take the evaluative to be solely a feature of concepts and/or terms, not of properties - unless perhaps they go deflationist about properties. See Eklund (2013) for other problems with the additional claim. 107).

${ }^{43}$ Judging from Ayer's examples, he would likely agree that these expanded contents have some factual content (1946, 
'beautiful', and 'hideous' (1946, 108-13). These are thick terms. So, Ayer would reject Representation, and is therefore not the target of the Anti-Disentangling Argument. McDowell agrees (1981, $217 \mathrm{fn.} \mathrm{29).}$

Argument (E): The only explanation for why 'good' would satisfy Bach's Schema is that its semantic content is a pro-concept — a concept that cannot represent a property unless it's combined with additional content. But target-non-cognitivists are committed to a view that's incompatible with the proconcept explanation. On their view, 'good' expresses an attitude or an emotion or has non-descriptive illocutionary force (e.g. in the prescriptive mood).

Contrary to this objection, non-cognitivism is consistent with the pro-concept explanation. By itself, the pro-concept explanation entails nothing about what kind of psychological state (if any) is expressed by uses of a predicate, or about what kind of illocutionary force the utterances have. So, the proconcept explanation could in principle be combined with target-non-cognitivism. For instance, consider C.L. Stevenson's view that "[t]he emotive meaning of a word is a tendency of a word, arising through the history of its usage, to produce (result from) affective responses in people” (1937, 23). Clearly, a word whose semantic content is a pro-concept could also have a tendency to produce (or result from) affective responses in people, and could thus have emotive meaning. Thus, Stevenson's theory is consistent with the pro-concept explanation. Of course, contemporary expressivists make a stronger claim than what Stevenson makes - they claim the semantic content of 'good' is constituted by an attitude. But this is also compatible with the pro-concept explanation, in at least two ways. The first is that the semantic content of 'good' could be constituted by both an attitude and a pro-concept. Expressivists need not claim that the attitude is the only thing constituting the semantic content of 'good'. ${ }^{44}$ And the pro-concept explanation need not claim that a pro-concept is the only thing constituting the semantic content of 'good'. A second

\footnotetext{
${ }^{44}$ Otherwise, hybrid-expressivism wouldn't be a form of expressivism. For example, Michael Ridge's ecumenical expressivism holds that the semantic contents of ethical claims are constituted by attitudes and beliefs (2006). The view mentioned above is weaker in that the extra element is not a belief or a proposition, but a pro-concept (which doesn't represent a property).
} 
option would be to claim that the attitude expressed by 'good' just is a pro-concept. If attitudes can be semantic contents, as expressivists claim, I see no reason why they couldn't be the sort of semantic contents that linguists have labeled pro-concepts.

Argument (F): If 'good' satisfies (ii), then there are properties such as goodness-to-someone-as-anend. And if there are such properties, then there's also a property of being good-in-some-way, since the latter merely quantifies over the former. But target-non-cognitivists cannot allow for any such property as goodness-in-some-way.

In reply, target-non-cognitivists can allow for the existence of goodness-in-some-way, provided EV is true. If EV is true, then goodness-in-some-way is merely a property that existentially quantifies over properties that target-non-cognitivists already accept. Target-non-cognitivists already accept the property of kindness, given their acceptance of Representation. And according to EV, kindness is identical to a property such as goodness-to-someone-as-an-end. So, goodness-in-some-way existentially quantifies over kindness, a property already countenanced by target-non-cognitivists. There's no reason for them to deny a property that merely existentially-quantifies over properties they already accept.

It's worth noting that the property of being good-in-some-way is distinct from any such property as goodness (or goodness-simpliciter). The former can be inferred through a single use of existentialintroduction, as Argument (F) assumes; the latter cannot be thusly inferred. Moreover, the former is possessed by nearly everything (Thomson 2008, 10); the latter is not. Given that they are distinct, it's consistent for target-non-cognitivists to reject the existence of goodness (or goodness-simpliciter), and yet accept goodness-in-some-way. This position would not be unique to target-non-cognitivism — it's shared by Judith Thomson, who is discussed next.

Argument (G): If target-non-cognitivists claim that 'good' satisfies (ii), then there's nothing distinctive about their view. Judith Thomson writes 
It is consistent to think both that there is no such property as goodness and that there is such a property as being a good umbrella - indeed, that is exactly the view I invite you to accept [...] But if [the expressivist] thinks that all is well with the property being a good umbrella, then what is distinctive about his Expressivism? There isn't much meat in it $(2008,38)$.

This worry can easily be framed with regard to the property of being good to someone as an end.

Thomson's concern is that there's nothing distinctive about the sort of expressivism that accepts such a property, since Thomson herself accepts it and she's not an expressivist.

It's worth noting that even if target-non-cognitivism couldn't be distinguished from Thomson's view, this would be just as much a problem for Thomson as it is for target-non-cognitivism. Nevertheless, there is an important difference. For target-non-cognitivists, the truncated predicate 'good' is incapable of representing a property. For Thomson, however, this truncated predicate can represent a property relative to context - it can represent a specific property, such as being a good umbrella or being good to someone as an end. For Thomson, context partly determines which of these specific properties is represented by the truncated predicate 'good' (2008, 32).

To sum up, we've seen that there's no reason for target-non-cognitivists to deny that 'good' satisfies clause (ii) of Bach's Schema. This means that there's no reason for them to accept Neglected Premise or Disentangling. Furthermore, we now have a potential model for how good can play a role in determining what property is represented by kind even if good cannot represent a property by itself. If EV is true, then kind is identical to an expanded content of 'good'. And the suggested model allows that good can help determine what property is represented by expanded contents of 'good' even if good can't represent a property by itself.

IV.5. Shapefulness. Even if proponents of EV need not accept Disentangling, they may be vulnerable to the Anti-Disentangling Argument if they accept Shapefulness for reasons other than Disentangling. I cannot examine all potential reasons for Shapefulness here. But I can show that no such reasons arise from EV per 
se. This section establishes that EV does not entail Shapefulness, and that proponents of EV can accept a primary argument against Shapefulness, based on outrunning data.

It's worth noting that the denial of Shapefulness is an instance of the shapelessness hypothesis - the claim that no non-evaluative concept could represent the same property as a thick concept (Roberts 2011, 505). This section therefore reveals that EV is consistent with the shapelessness hypothesis.

Can proponents of EV deny Shapefulness? Roberts has argued that some dependence views entail Shapefulness, independently of Disentangling $(2011,507$; 2013, 682). But EV is a form of Separabilism that does not entail Shapefulness. Consider our sample instance of EV, where kind is identical to good-[tosomeone-as-an-end]. This sort of account does not involve any non-evaluative concepts that would be sufficient for kind. Good-[to-someone-as-an-end] is an evaluative concept, and as far as EV is concerned, it may be the only concept that is sufficient for kind. Therefore, EV doesn't require that there could be a nonevaluative concept that represents the same property as kind, and so doesn't require Shapefulness.

To solidify this, notice that proponents of EV can accept a primary argument against Shapefulness. The rejection of Shapefulness is often motivated by the claim that extensions of thick concepts outrun nonevaluative classifications. Kirchin writes

Just think about the various types of kind action there are: opening doors for people, telling the truth, telling a "white" lie, giving someone some sweets, refraining from giving sweets for some other reason, and so on $(2010,5)$.

Kirchin then spells out the example of giving "sweets" as follows:

[I]t might be cruel to refrain from sharing chocolate with a young child who desperately wants it, but it can be kind if, in addition, we are acting because there is some risk of her teeth rotting in the future. In more complicated situations it might be kinder to share, despite the risk of tooth rot, because, say, someone has hurt her feelings and she needs comforting $(2010,6)$.

Since our judgments about kindness are affected by non-evaluative modifications that could go on indefinitely, it might seem unlikely for there to be a non-evaluative concept that represents the same property as kind. This may initially support the rejection of Shapefulness. 
But the same argument could be accepted by proponents of EV. Notice that Kirchin's examples equally affect our judgments about whether the action would be good to someone as an end. If there's serious risk of tooth-decay and the child needs no comforting, then refraining from sharing the chocolate could be good to the child as an end (depending on one's intention). Similarly, opening a door for someone, telling the truth, or telling a white lie, could also be good to that person as an end, depending on one's intention. Thus, the sort of data that calls Shapefulness into doubt is just as persuasive if kind is identical to good-[to-someone-as-an-end]. Proponents of EV can accept the outrunning argument against Shapefulness. Whether this argument adequately supports the rejection of Shapefulness is another matter, as Kirchin himself points out (2010).

Despite the outrunning data, there might be reasons for accepting Shapefulness, which have nothing to do with Disentangling or EV. But the modest point of this section stands: EV does not by itself require Shapefulness. It should be noted, however, that EV also does not prohibit anyone from accepting Shapefulness. One could, for example, claim that good-[to-someone-as-an-end] (i.e. kind) represents the same property as a non-evaluative concept, like increases-another's-happiness-as-an-end. This sort of claim is perfectly open to proponents of EV, but not forced on them.

IV.6. Conclusion. This paper has explained and defended a new Separabilist account - the Expansion View (or EV) — which holds that thick concepts are expanded contents of thin terms. We've seen that EV is distinct from the only kind of Separabilism taken seriously in the literature, and that it has many features that Inseparabilists want from an account of thick concepts. Most notably, EV provides proponents with a new strategy to avoid Disentangling: they can allow thin concepts to play a role in determining what 
properties are represented by thick concepts, even if thin concepts don't represent properties by

themselves. ${ }^{45}$

\section{References}

Almotahari, M. and A. Hosein. 2015. "Is Anything Just Plain Good?” Philosophical Studies 172, 1485-1508.

Ayer, A.J. 1946. Language, Truth, and Logic. New York: Dover.

Bach, K. 1994. “Conversational Impliciture,” Mind and Language 9, 124-62.

Bach, K. 2006. “The Excluded Middle: Semantic Minimalism without Minimal Propositions,” Philosophy and Phenomenological Research, 435-42.

Bach, K. 2012. "Context Dependence" in The Continuum Companion to the Philosophy of Language, eds. M. Garcia-Carpintero and M. Kolbel, 153-84.

Blackburn, S. 1992. "Through Thick and Thin,” Proceedings of the Aristotelian Society 66 (suppl.), 284-99.

Borg, E. 2007. "Minimalism versus Contextualism in Semantics," in Context-Sensitivity and Semantic

Minimalism, eds. G. Preyer and G. Peter, Oxford: Oxford University Press, 339-60.

Burton, S. 1992. “'Thick’ Concepts Revisited,” Analysis 52, 28-32.

Cappelen H. and E. Lepore. 2004. Insensitive Semantics: A Defense of Semantic Minimalism and Speech Act Pluralism. Oxford: Blackwell Publishers.

Chappell, T. 2013. “There Are No Thin Concepts,” in Thick Concepts, ed. S. Kirchin, Oxford: Oxford University Press, 182-96.

Dancy, J. 1995. "In Defense of Thick Concepts," Midwest Studies in Philosophy 20, 263-79.

Dancy, J. 2004. Ethics without Principles. Oxford: Oxford University Press.

Dancy, J. 2013. "Practical Concepts," in Thick Concepts, ed. S. Kirchin, Oxford: Oxford University Press, 44-59.

Eklund, M. 2011. “What Are Thick Concepts?” Canadian Journal of Philosophy 41, 25-50.

Eklund, M. 2013. "Evaluative Language and Evaluative Reality," in Thick Concepts, ed. S. Kirchin, Oxford: Oxford University Press, 161-81.

${ }^{45}$ Special gratitude goes to Matti Eklund for helpful comments and willingness to discuss many drafts of this paper. I am also indebted to Debbie Roberts, Pekka Väyrynen, Carl Ginet, Simon Kirchin, Nicholas Sturgeon, Nico Silins, and several anonymous reviewers for valuable discussions and feedback. And finally, I thank the Stockdale Center at the US Naval Academy for their generous support, which allotted me enough time to finalize this article. The viewpoints expressed in this article do not reflect the official positions of any US government agency. 
Elstein D. and T. Hurka. 2009. "From Thick to Thin: Two Moral Reduction Plans," Canadian Journal of Philosophy 39, 515-35.

Finlay, S. 2014. Confusion of Tongues: A Theory of Normative Language, Oxford: Oxford University Press.

Geach, P. 1956. "Good and Evil,” Analysis 17, 32-42.

Gibbard A. 1990. Wise Choices, Apt Feelings, Cambridge, Mass: Harvard University Press.

Gibbard, A. 1992. "Thick Concepts and Warrant for Feelings," Proceedings of the Aristotelian Society 66 (suppl.), 267-83.

Hare, R.M. 1952. The Language of Morals, Oxford: Clarendon Press.

Hare, R.M. 1963. Freedom and Reason, Oxford: Oxford University Press.

Hurley, S. 1989. Natural Reasons, Oxford: Oxford University Press.

Kirchin, S. 2010. “The Shapelessness Hypothesis,” Philosophers' Imprint 10, 1-28.

Kirchin, S. 2013. "Thick Concepts and Thick Descriptions," in Thick Concepts, ed. S. Kirchin, Oxford: Oxford University Press, 60-77.

Kirchin, S. 2017. Thick Evaluation. Oxford: Oxford University Press.

Kyle, B.G. 2013a. “How Are Thick Terms Evaluative?” Philosophers' Imprint 13, 1-20.

Kyle, B.G. 2013b. "Knowledge as a Thick Concept: Explaining Why the Gettier Problem Arises," Philosophical Studies 165, 1-27.

Kyle, B.G. 2015. "Review of The Lewd, the Rude, and the Nasty: A Study of Thick Concepts in Ethics, by Pekka Väyrynen," Philosophical Quarterly 65, 576-82.

Kyle, B.G. 2016. "Thick Concepts," The Internet Encyclopedia of Philosophy, URL = <https://www.iep.utm.edu/thick-co/> accessed 4/3/2019.

Kyle, B.G. 2017. “Courage, Cowardice, and Maher's Misstep,” Canadian Journal of Philosophy 47, 565-87.

Levinson, S. 2000. Presumptive Meanings. Cambridge: MIT Press.

McDowell, J. 1981. “Non-Cognitivism and Rule Following," in Wittgenstein: To Follow a Rule, Holtzman and Leich (eds.), New York: Routledge, 141-62.

Millgram, E. 1995. "Inhaltsreiche ethische Begriffe und die Unterscheidung zwischen Tatsachen und Werten,” in Fehige and Meggle, eds., Zum moralischen Denken, Frankfurt a. M.: Suhrkamp, 354-88. 
Peace, F.J. 2017. “Who Needs 'Just Plain' Goodness? A Reply to Almotahari and Hosein,” Philosophical Studies 174, 2991-3004.

Payne, A. 2005. “A New Account of Thick Concepts," The Journal of Value Inquiry 39, 89-103.

Ridge, M. 2006. "Ecumenical Expressivism: Finessing Frege," Ethics 116, 302-36.

Roberts, D. 2011. "Shapelessness and the Thick," Ethics 121, 489-520.

Roberts, D. 2013. “Thick Concepts,” Philosophy Compass 8, 677-88.

Roberts, D. 2015. Review of The Lewd, the Rude, and the Nasty by Pekka Väyrynen, Ethics 125, 910-15.

Roberts, D. 2017. “Depending on the Thick," Aristotelian Society Supplementary Volume 91, 197-220.

Soames, S. 2008. "Drawing the Line Between Meaning and Implicature - and Relating Both to Assertion," Nous 42, 440-65.

Soames, S. 2010. Philosophy of Language. Princeton: Princeton University Press.

Stevenson, C. L. 1937. “The Emotive Meaning of Ethical Terms,” Mind 46, 14-31.

Szabo, Z. 2001. "Adjectives in Context," in Perspectives on Semantics, Pragmatics, and Discourse, Harrish and Kenesei (eds.), Amsterdam: John Benjamins, 119-46.

Tappolet, C. 2004. “Through Thick and Thin: Good and Its Determinates,” Dialectica 58, 207-21.

Thomson, J. 2008. Normativity. Chicago, Ill: Open Court.

Tomassi, P. 1999. Logic. London: Routledge.

Väyrynen, P. 2011. “Thick Concepts and Variability,” Philosophers’ Imprint 11, 1-17.

Väyrynen, P. 2013. The Rude, the Lewd, and the Nasty: A Study of Thick Concepts in Ethics, Oxford: Oxford University Press.

Väyrynen, P. 2016. “Thick Ethical Concepts,” The Stanford Encyclopedia of Philosophy (Winter 2016 Edition), Zalta (ed.), URL $=<$ https: / / plato.stanford.edu/archives/win2016/entries/thick-ethicalconcepts $>$ accessed 4/3/2019.

Wilson, D. 2011. "The Conceptual-Procedural Distinction: Past, Present, and Future," in Procedural Meaning: Problems and Perspectives, Escandell-Vidal, Leonetti, and Ahern (eds.), Bingley, UK: Emerald Group Publishing.

Zangwill, N. 2006. "Moral Epistemology and the Because Constraint," in Contemporary Debates in Moral Theory, Dreier (ed.), Oxford, UK: Blackwell. 263-81. 